\title{
Familial Clustering of Major Depression and Anxiety Disorders in Australian and Dutch Twins and Siblings
}

\author{
Christel M. Middeldorp, ${ }^{1,2}$ Andrew J. Birley, ${ }^{3}$ Danielle C. Cath, ${ }^{2}$ Nathan A. Gillespie, ${ }^{3}$ Gonneke Willemsen, ${ }^{1}$ \\ Dixie J. Statham, ${ }^{3}$ Eco J. C. de Geus, ' J. Gavin Andrews, ${ }^{4}$ Richard van Dyck, ${ }^{2}$ A. Leo Beem, ${ }^{\prime}$ \\ Patrick F. Sullivan, ${ }^{5}$ Nicholas G. Martin, ${ }^{3}$ and Dorret I. Boomsma' \\ ' Department of Biological Psychology, Vrije Universiteit Amsterdam, Amsterdam, the Netherlands \\ ${ }^{2}$ Department of Psychiatry,Vrije Universiteit Medical Center, Amsterdam, the Netherlands \\ ${ }^{3}$ Genetic Epidemiology Unit, Queensland Institute of Medical Research, Brisbane, Australia \\ ${ }^{4}$ Clinical Research Unit for Anxiety and Depression, University of New South Wales, Darlinghurst, Australia \\ ${ }^{5}$ Departments of Genetics and Psychiatry, University of North Carolina, Chapel Hill, North Carolina, United States of America
}

$T_{\text {hin }}^{\text {he }}$ he aim of this study was to investigate familial influences and their dependence on sex for panic disorder and/or agoraphobia, social phobia, generalized anxiety disorder and major depression. Data from Australian ( $N=2287)$ and Dutch $(N=1185)$ twins and siblings who were selected for a linkage study and participated in clinical interviews to obtain lifetime Diagnostic and Statistical Manual of Mental Disorders (4th ed.; DSM-IV) diagnoses were used. In a liability model, tetrachoric correlations were estimated in sibling pairs and sex differences between sibling correlations were tested. For each diagnosis, the sibling correlations could be constrained to be equal across the Australian and Dutch samples. With the exception of panic disorder and/or agoraphobia, all sibling correlations were the same for brother, sister and opposite-sex sibling pairs and were around .20. For panic disorder and/or agoraphobia, the correlation was .23 in brother and sister pairs, but absent in opposite-sex sibling pairs. From these results it can be concluded that upper heritability estimates, based on twice the correlations in the sibling pairs, vary between $36 \%$ (major depression) and 50\% (social phobia). Furthermore, different genetic risk factors appear to contribute to the vulnerability for panic disorder and/or agoraphobia in men and women. No other sex differences were found.

Anxiety disorders and major depression (MDD) are common disorders. In epidemiological studies, lifetime prevalences in women are found to be around $30 \%$ for some kind of anxiety disorders and around $20 \%$ for MDD (Bijl et al., 1998; Kessler et al., 1994). Although these prevalences are lower in men, they are still high with figures ranging between $14 \%$ and $19 \%$ for anxiety disorders and between $11 \%$ and $13 \%$ for MDD (Bijl et al., 1998; Kessler et al., 1994). These prevalences may be even higher as cross-sectional surveys are biased by recall problems. When recall bias is considered, the prevalence of lifetime MDD is estimated at $30 \%$ in men and $40 \%$ in women (Kruijshaar et al., 2005). These disorders constitute a huge public health problem, mainly due to the chronic and disabling course, but in the case of MDD, also as a result of the increased risk for other major diseases such as cardiac mortality (Musselman et al., 1998; Penninx et al., 2001).

Consequently, the etiology of these disorders is an important topic of research. Over the last 20 years, several family and twin studies have been performed to investigate the influence of familial factors on anxiety and depression. In the description of the results, we will focus on MDD, panic disorder and/or agoraphobia, social phobia and generalized anxiety disorder (GAD). Sullivan et al. (2000) and Hettema, Neale, et al. (2001) discussed the results of family and twin studies on lifetime diagnoses of MDD and anxiety disorders respectively and performed a metaanalysis when possible. They included studies in which the disorders were defined by operationalized diagnostic criteria, such as the Diagnostic and Statistical Manual of Mental Disorders (3rd ed.; DSM-III; American Psychiatric Association, 1980), DSM-III-R (3rd ed., rev.; American Psychiatric Association, 1987) or DSM-IV (4th ed.; American Psychiatric Association, 1994). The family studies that compared the risk on MDD or anxiety disorders between first-degree relatives of probands and controls showed a significant familial risk with summary odds ratios for these disorders varying between 2.8

Received 20 June, 2005; accepted 24 August, 2005.

Address for correspondence: Christel Middeldorp, Vrije Universiteit Amsterdam, Department of Biological Psychology, Van der Boechorststraat 1, 1081 BT Amsterdam, the Netherlands. E-mail: Cm.middeldorp@psy.vu.nl 
and 6.1 (Hettema, Neale, et al., 2001; Sullivan et al., 2000). However, data were collected in clinical samples in most family studies which may have biased the results. Twin studies are often population-based. A meta-analysis of five twin studies performed in different continents showed that familial resemblance in MDD was entirely due to shared genes, with genetic factors explaining $37 \%$ of the variance (Sullivan et al., 2000). For the anxiety disorders, meta-analyses could only be performed on panic disorder and GAD due to the scarcity of twin studies on this issue (Hettema, Neale, et al., 2001). Genetic factors appeared to explain $43 \%$ of the variance in panic disorder and $32 \%$ in GAD (Hettema, Neale, et al., 2001). These meta-analyses were based on two large community-based twin samples only, which are both from the United States (Hettema, Neale, et al., 2001). The Virginia Twin Registry originally consisted of female twins, but has been extended with male twins and twins of oppositesex (Kendler \& Prescott, 1999). The Vietnam Era Twin Registry consists of male twins only (Scherrer et al., 2000). In the Virginia Twin Registry, phobias were also investigated. It was found that, overall, familial resemblance was due to shared genetic influences, which explained $30 \%$ and $39 \%$ of the variance in women for social phobia and agoraphobia respectively and 20\% and $37 \%$ of the variance in men (Kendler, Myers, et al., 2001; Kendler et al., 1992).

Sex differences in the influence of familial factors is an important issue when investigating specific risk factors, for example, in linkage studies. In the absence of sex differences, data from men and women can be analyzed simultaneously, which increases statistical power. The majority of the studies indicate that genetic effects influence variation in MDD in men and women to the same extent with most, but not all, genetic influences shared in men and women (Kendler, Gardner, Neale, et al., 2001; Sullivan et al., 2000). Sex differences in the etiology of anxiety disorders have been studied in the Virginia Twin Registry only. No consistent differences in genetic architecture between men and women were found in GAD, social phobia and panic disorder (Hettema, Prescott, et al., 2001; Hettema et al., 2005; Kendler, Gardner, \& Prescott, 2001; Kendler et al., 2002; Kendler et al., 2003). In agoraphobia, results indicated that the genes conveying the risk are probably not entirely the same (Kendler et al., 2002).

This overview of the current literature shows that knowledge about familial influences on anxiety disorders and MDD and especially about sex differences in these influences is limited. In this article, data on lifetime panic disorder and/or agoraphobia, social phobia, GAD and MDD, all defined according to DSM-IV (American Psychiatric Association, 1994) criteria, were analyzed in samples of male, female and opposite-sex dizygotic (DZ) twin and sibling pairs from the Australian and Netherlands population-based Twin Registers. The participants were selected for a linkage study on anxiety and depression, based on scores on self-report measures. As these scores were available for the total samples of twins and their siblings, a correction for ascertainment bias could be carried out (Little \& Rubin, 1987).

\section{Material and Methods \\ Subjects}

Data were collected in the Australian and Netherlands Twin Registers as part of a project aiming to find the genes underlying the susceptibility to anxiety and depression. For a detailed description of the data collection, see Kirk et al. (2000), Boomsma et al. (2000), and Middeldorp et al. (in press). In short, in 1998, the most informative families for a linkage study on anxiety and depression were selected. These were families with sibling pairs scoring extreme discordant (low-high) or concordant (high-high and low-low) on a quantitative scale that correlates with a diagnosis of MDD or an anxiety disorder (Dolan \& Boomsma, 1998; Eaves \& Meyer, 1994; Risch \& Zhang, 1995). In Australia, the selection variable was a normalized neuroticism score, adjusted for age and sex, obtained in 1989. This score was available for 18,578 twins, siblings and adult offspring of twins (Kirk et al., 2000). In the Netherlands, the selection variable was a genetic factor score expressing a subject's genetic susceptibility to 'anxious depression'. These factor scores were calculated as a weighted sum of the scores on four measures of neuroticism, anxiety and depression assessed on three different occasions (1991, 1993 and 1997). The weights were derived from a multivariate genetic analysis on these four scales and were different for men and women. The calculation of the factor scores is described in detail by Boomsma et al. (2000). A factor score was available for 7836 Dutch twins and siblings (Middeldorp et al., in press). In both Australia and the Netherlands, extreme discordant and concordant scoring sibling pairs were asked to participate in a diagnostic psychiatric interview. In addition, all other twins and siblings in these families, regardless of their value on the selection variable, were invited to take part in the study.

In the Australian and Netherlands Twin Registers, 2918 and 1517 subjects respectively were approached to participate in the interview. In Australia, 256 subjects declined to participate and 192 subjects could not be contacted (Kirk et al., 2000). In the Netherlands, 154 subjects refused and 107 subjects could not be contacted (Middeldorp et al., in press). Eventually, 2470 Australian and 1256 Dutch individuals were interviewed. Thus, a participation rate of around $90 \%$ was achieved in both samples.

Analyses were carried out on the data from DZ twins, siblings and, in the Australian sample, adult children of twins, who have a score on the selection variable and at least one additional full sibling with a score on the selection variable. Half siblings, twin pairs with unknown zygosity, and subjects without 
additional siblings are excluded. Monozygotic (MZ) twins were included if there was a sibling available with a score on the selection variable. This resulted in a total population for the analyses of 11,291 Australian and 5836 Dutch subjects with scores on the selection variables of which 2287 Australian and 1185 Dutch subjects had participated in the interview.

\section{Instruments}

In Australia, neuroticism was measured using the revised short form of the Revised Eysenck Personality Questionnaire (EPQ-R) with a 12-item neuroticism scale (Eysenck et al., 1985). In the Netherlands, genetic-factor scores were calculated from the scores on the neuroticism and somatic anxiety scales of the Amsterdamse Biografische vragenslijst (Wilde, 1970), the Spielberger State Trait Anxiety Inventory - Trait version (STAI; Spielberger et al., 1970; Van der Ploeg et al., 1979), the Beck Depression Inventory (BDI; Beck et al., 1974) and the Young Adult Self-Report (YASR; Achenbach, 1990; Verhulst et al., 1997). The 30 -item neuroticism scale is similar in content to the neuroticism scale of the Eysenck Personality Questionnaire (Eysenck \& Eysenck, 1964).

In both samples, all offspring of selected families were asked to participate in a telephone interview, during which the computerized version of the Composite International Diagnostic Interview (CIDI; World Health Organization, 1992) was administered to obtain lifetime DSM-IV (American Psychiatric Association, 1994) diagnoses of mood and anxiety disorders. The CIDI is a fully standardized diagnostic interview. No information on the reliability and validity of the Dutch version of the CIDI is available, but good reliability and validity have been reported for the English version (Andrews \& Peters, 1998). All interviewers were trained by the Dutch and Australian World Health Organization training centers. In order to minimize observer bias, interviewers were unaware of interviewees' scores on the initial selection variables throughout the study. According to the diagnostic algorithm as obtained with the CIDI, subjects can be classified in three categories: 'not affected', 'affected', and 'fulfilling the positive criteria, but not the exclusion criteria'. The latter category consists of subjects with more than one anxiety disorder at the same time, subjects who exhibit symptoms of GAD exclusively during a depressive episode, and subjects who fulfill the criteria for an anxiety disorder but did not seek help for their symptoms. Subjects in this category were classified as affected as well.

We analyzed diagnoses of MDD, GAD, social phobia, panic disorder with or without agoraphobia and agoraphobia without a history of panic disorder. Subjects with one of the latter three diagnoses were grouped together.

\section{Statistical Methods}

The CIDI was administered in a selected sample, so a correction for ascertainment was applied by including the selection variables in the analyses (Little \& Rubin, 1987). This correction assumes that in the total sample, missing values are only due to selection variables and random factors (Little \& Rubin, 1987). Therefore for all diagnoses, a bivariate analysis was carried out including the scores of the selection variables of all participants and the information on the diagnosis of the selected samples.

The saturated bivariate model thus included neuroticism in the Australian sample, the genetic factor scores in the Dutch sample and one of the diagnoses under study in both the Australian and Dutch sample; that is, MDD, GAD, social phobia or panic disorder and/or agoraphobia. The diagnoses are assessed on a dichotomous scale. The selection variables were analyzed as ordinal data by dividing the scores in four categories based on the 25th, 50th and 75 th percentile. Thresholds for the selection variables and for the diagnosis were estimated separately for the Australian and Dutch sample and for men and women. Polychoric (cross) correlations for the selection variables and the diagnosis were calculated for DZ and sibling pairs of brothers, sisters and siblings of opposite-sex. The correlations for the selection variables and the cross-correlations between the selection variables and the diagnosis were estimated separately in the Australian and Dutch samples. For each diagnosis we explicitly tested whether the Dutch and Australian correlations between brothers, sisters and opposite-sex siblings were similar.

Sex differences in familial influences on the diagnoses were analyzed in two ways. First, quantitative differences between men and women were investigated by testing whether the correlations were different in same-sex male and female sibling pairs. Second, qualitative differences were investigated. If the same familial factors are of importance in men and women, the correlation of opposite-sex sibling pairs should not differ significantly from the product of the square roots of correlations in men and women. This formula can be derived from the tracing rules of path analysis (Neale $\&$ Cardon, 1992). After analyzing sex differences, the significance of the sibling correlations for the diagnosis was tested by fixing this correlation to zero. A significant correlation indicates that members of a sibling pair are more alike than would be expected by chance.

Statistical analyses were performed on raw data using the raw likelihood method implemented in the software program Mx (Neale et al., 1999). To test whether correlations were significantly different between the groups of sibling pairs or from zero, the likelihood of the model in which all parameters were estimated was compared to the likelihood of the model in which the parameters were constrained to be equal across different groups or to zero. The difference between -2 *loglikelihood of two models is distributed asymptotically as $\chi^{2}$. The degrees of freedom for these tests are equal to the difference in parameters being estimated. Utilizing the principle of 
Table 1

Age and Frequencies of Lifetime MDD, Panic Disorder and/or Agoraphobia, Social Phobia and GAD in the Selected Australian and Dutch Samples

\begin{tabular}{|c|c|c|c|c|}
\hline & \multicolumn{2}{|c|}{ Australia } & \multicolumn{2}{|c|}{ The Netherlands } \\
\hline & Males $(N=885)$ & Females $(N=1402)$ & Males $(N=499)$ & Females $(N=686)$ \\
\hline Age at interview $(S D)$ & $41.8(10.4)$ & $42.4(11.3)$ & $28.5(10.8)^{*}$ & $28.6(11.0)^{*}$ \\
\hline $\operatorname{MDD}(\%)$ & $191(21.6)$ & $374(26.7)$ & $46(9.3)$ & $137(20.0)$ \\
\hline Panic disorder and/or agoraphobia (\%) & $79(8.9)$ & $197(14.1)$ & $19(3.8)$ & $79(11.5)$ \\
\hline Social phobia (\%) & $85(9.6)$ & $142(10.2)$ & $12(2.4)$ & $38(5.5)$ \\
\hline GAD $(\%)$ & $71(8.0)$ & $140(10.0)$ & $18(3.6)$ & $52(7.6)$ \\
\hline
\end{tabular}

Note: *Mean age of the three waves of data collection $(1991,1993,1997)$.

parsimony, the most restrictive model was accepted as the best fitting model if the difference between a nested and a more comprehensive model was not significant (Neale \& Cardon, 1992). Analyses were carried out on all possible pairs (Hottenga et al., 2005).

\section{Results}

Table 1 shows the mean ages at the time of the interview and the frequencies of the diagnoses in men and women in the Australian and Dutch samples. The Australian subjects were significantly older than the Dutch participants. This age difference probably explains the higher frequencies of all diagnoses in the Australian sample. However, the difference in frequencies could also be partly explained by coincidental differences in the selection. In Australia, $43 \%$ of the interviewed subjects had an extreme neuroticism score, while in the Netherlands a smaller proportion of the interviewed subjects, namely $32 \%$, had an extreme genetic factor score. Earlier analyses have shown that subjects with high scores on neuroticism (Australia) or on the questionnaires used to calculate the genetic factor scores (the Netherlands) are more likely to get a diagnosis (Kirk et al., 2000; Middeldorp et al., in press). In both countries, all disorders were more common in women than in men.

Differences between twins and siblings were also investigated in both countries. Twins and siblings did not differ regarding their scores on the selection variables. Nor was the percentage of subjects who got a diagnosis different in twins and siblings. These results indicate that in both the Australian and Dutch samples the twin and sibling populations are equivalent to each other.

Table 2 shows for each diagnosis the differences in $-2 * \log$ likelihood between the different models. For each diagnosis, the correlations could be constrained to be equal across the Australian and Dutch populations. Further analyses were therefore performed on the combined samples. First, the correlations were constrained to be equal across the male and female same-sex sibling pairs. Second, the correlation between the opposite-sex sibling pairs was constrained to be equal to the product of the square roots of correlations in the same-sex pairs. Next, the correlations were fixed to zero. This last test had to be performed on one, two or three correlations, depending on the outcome of the first two steps in the model-fitting procedure. Table 3 gives the estimates of the correlations and confidence intervals in the full bivariate model as well as in the best fitting model resulting from the model-fitting procedure. For the sake of clarity, only the results for the diagnoses are shown and the results for the selection variables are left out of consideration. For MDD, social phobia and GAD, the correlations in the brothers, sisters and opposite-sex pairs could be constrained to be equal and the final correlations were

Table 2

Tests of Equality of Correlations ( $r$ ) between (1) Australia and the Netherlands, (2) Brother-Brother and Sister-Sister Pairs, (3) Same-Sex and Opposite-Sex Pairs and (4) for the Overall Significance of the Correlations

\begin{tabular}{lcccc}
\hline & 1. $r$ Aus $=r \mathrm{NL}(\Delta d f=3)$ & 2. $r \mathrm{M}=r \mathrm{~F}(\Delta d f=1)$ & 3. $r \mathrm{OS}=r \mathrm{SS}(\Delta d f=1)$ & $4 . r=0(\Delta d f=1)^{\mathrm{a}}$ \\
\hline $\mathrm{MDD}$ & 2.60 & .03 & .61 & $24.32^{* * *}$ \\
Panic disorder and/or agoraphobia & 1.53 & 1.30 & $4.36^{*}$ & $10.04^{* *} / .92$ \\
Social phobia & 3.00 & .01 & 2.70 & $18.07^{* * *}$ \\
GAD & 2.41 & .79 & 1.01 & $11.37^{* * *}$ \\
\hline
\end{tabular}

Note: $\mathrm{M}$ : correlations in male twin pairs, $\mathrm{r}$ : correlations in female twin pairs, $\mathrm{rOS}$ : correlations in opposite sex pairs, rSS: correlations in same-sex pairs.

${ }^{*} p<.05,{ }^{* *} p<.01,{ }^{* * *} p<.001$

$\mathrm{a}=$ For panic disorder and/or agoraphobia, the correlation between opposite-sex sibling pairs was not equal to the correlation in same-sex sibling pairs. Therefore, two correlations were tested, i.e., the correlation in same-sex sibling pairs (left $\chi^{2}$ : significant) and the correlation in the opposite-sex sibling pairs (right $\chi^{2}$ : not significant).

The test-statistic is based on the difference in $-2^{*}$ loglikelihood between nested models and is distributed as $\chi^{2}$ with degrees of freedom ( $d f$ ) as shown. 
Table 3

Maximum-Likelihood Estimates of Tetrachoric Sibling Correlations (and 95\% Confidence Intervals) Under the Full and the Best Fitting Model

\begin{tabular}{llccccc}
\hline & \multicolumn{3}{c}{ Full model } & \multicolumn{3}{c}{ Best fitting model } \\
\hline (N pairs total/N pairs selected) & $\begin{array}{c}\text { Brothers } \\
(3134 / 497)\end{array}$ & $\begin{array}{c}\text { Sisters } \\
(5913 / 1007)\end{array}$ & $\begin{array}{c}\text { OS siblings } \\
(8145 / 1403)\end{array}$ & Brothers & Sisters & 0S siblings \\
\hline MDD & $.22(.04-.39)$ & $.20(.08-.31)$ & $.15(.05-.25)$ & $.18(.11-.25)$ & $.18(.11-.25)$ & $.18(.11-.25)$ \\
Panic disorder and/or agoraphobia & $.15(-.14-.42)$ & $.25(.10-.39)$ & $-.01(-.18-.16)$ & $.23(.11-.36)$ & $.23(.11-.36)$ & $0(-.18-.16)$ \\
Social phobia & $.33(.04-.63)$ & $.34(.17-.49)$ & $.15(-.02-.31)$ & $.25(.14-.35)$ & $.25(.14-.35)$ & $.25(.14-.35)$ \\
GAD & $.15(-.14-.40)$ & $.14(-.06-.33)$ & $.26(.10-.41)$ & $.20(.09-.31)$ & $.20(.09-.31)$ & $.20(.09-.31)$ \\
\hline
\end{tabular}

significant with estimates around .20 (Table 2 and 3). In panic disorder and/or agoraphobia, the correlation between the opposite-sex pairs was significantly different from the correlation calculated in the same-sex brother and sister pairs. The correlation in the brother and sister pairs was estimated at .23 , whereas the correlation between the opposite-sex pairs could be fixed to zero.

\section{Discussion}

The resemblances found in these combined analyses of Australian and Dutch twin and sibling data indicate significant familial risk for the development of MDD, panic disorder and/or agoraphobia, social phobia and GAD. No sex differences were found in the familial influences on MDD, social phobia and GAD. The results for panic disorder and/or agoraphobia indicate that familial factors contribute to a similar degree to the variance in liability in men and women, but the familial factors themselves are different between the sexes. Because MZ twin pairs were not selected for this study, it is, strictly speaking, not possible to decide whether the familial resemblance is due to genetic or common environmental factors and only upper limits for heritability estimates, based on twice the DZ/sibling pair correlations, can be given. These upper heritability estimates vary between $36 \%$ (major depression) and 50\% (social phobia). However, earlier research in these samples indicates that twin resemblance for self-report measures of neuroticism, anxiety and depression is entirely explained by genetic factors (Boomsma et al., 2000; Jardine et al., 1984; Martin et al., 1988). This also accounts, in general, for twin studies on DSM anxiety disorders and MDD (Hettema, Neale, et al., 2001; Sullivan et al., 2000). Therefore, we think that it is reasonable to assume that our results also indicate genetic and not common environmental influences on MDD, panic disorder and/or agoraphobia, social phobia and GAD.

The upper heritability estimates are comparable to earlier studies (Hettema, Neale, et al., 2001; Sullivan et al., 2000). Regarding the sex differences, the results were somewhat different from the results of the Virginia Twin Registry. We did not find any sex-specific genetic influences for MDD in contrast to Kendler, Gardner, Neale, et al. (2001), who found that
$50 \%$ of the genes that influence the vulnerability to MDD might be different in men and women. By controlling for unreliability of measurement, their study probably had more power to detect sex differences. Furthermore, we found sex-specific genetic risk factors for panic disorder and/or agoraphobia, whereas their analyses of panic syndromes showed no sex differences (Kendler, Gardner, \& Prescott, 2001). However, their results for agoraphobia also suggested sex-specific genetic risk factors (Kendler et al., 2002). In the current study, subjects with panic disorder and/or agoraphobia were considered to be one group, containing over $50 \%$ of subjects with agoraphobia with or without panic disorder. This may have caused the differential outcomes.

This is the first nonclinical twin-family study outside the United States that investigates not only familial risk in anxiety disorders as defined according to the DSM-IV (American Psychiatric Association, 1994) but also the presence of sex differences in familial influences. The sample size is large due to the combination of the Australian and Dutch twin-family samples. Combining these samples was possible as the way in which the twins and siblings were recruited was similar. Moreover, differences between the correlations in the two samples were statistically tested and appeared to be absent.

Still, one might argue that the samples were not comparable as the Australian subjects were older than the Dutch participants. As a consequence, more Australian twins and siblings were diagnosed with one or more disorders. However, a recent study found that genetic and environmental determinants of anxiety and depression hardly show any change with age, so this age difference has probably not influenced our results (Gillespie et al., 2004). Another limitation is that test-retest data were not available for our samples, which made it impossible to estimate the reliability of the lifetime interviews. In studies in which unreliability of measurement was taken into account, heritability estimates were around $50 \%$ for phobias (Kendler et al., 1999 ) and $66 \%$ for MDD (Foley et al., 1998). These studies demonstrate that in our study the effect of familial influences might be underestimated. Finally, despite the large sample size, power to detect sex 
differences was relatively small as can be seen from the relatively broad confidence intervals (Table 3 ).

To summarize, in these two large family studies performed on different continents, MDD, panic and/or agoraphobia, social phobia and GAD show sibling correlations around .20, suggesting that genetic factors explain approximately $40 \%$ of the variance. Panic and/or agoraphobia might be influenced by different familial factors in men and women. No sex differences were found for the other disorders. Overall, these results are in accordance with earlier studies. This means for future linkage and association studies that analyses on panic disorder and/or agoraphobia should be carried out in men and women separately. This does not appear to be necessary for MDD, social phobia and GAD in which the results suggest considerable overlap in genetic risk factors for men and women.

\section{Acknowledgments}

We thank the twins and their relatives for their participation. The Australian study was approved by the QIMR Human Research Ethics Committee and the Dutch study by the Ethics Committee of the Vrije Universiteit Hospital. We thank Scott Gordon for computer support. We acknowledge the role of Dr Andrew Heath and NIH grants (AA07535 and AA07728) in earlier projects in which selection variables were collected. This study was funded by the Australian National Health and Medical Research Council (971232, 339450) and Gemini Genomics Pty Ltd (now Sequenom Inc.). The Dutch study was supported by the Netherlands Organization for Scientific Research NWO/ZonMW (940-37-024, 904-61-090, 575-25-006). The analyses have been made possible by a travel scholarship to CMM from the GenomEUtwin project which is funded under a European Union Framework 5 grant and by an NIH grant to PFS (MH059160).

\section{References}

Achenbach, T. M. (1990). The Young Adult Self Report. Burlington, VT: University of Vermont, Department of Psychiatry.

American Psychiatric Association. (1980). Diagnostic and statistical manual of mental disorders (3rd ed.). Washington, DC: Author.

American Psychiatric Association. (1987). Diagnostic and statistical manual of mental disorders (3rd ed., rev.). Washington, DC: Author.

American Psychiatric Association. (1994). Diagnostic and statistical manual of mental disorders (4th ed.). Washington, DC: Author.

Andrews, G., \& Peters, L. (1998). The psychometric properties of the Composite International Diagnostic Interview. Social Psychiatry and Psychiatric Epidemiology, 33, 80-88.
Beck, A. T., Rial, W. Y., \& Rickels, K. (1974). Short form of depression inventory: Cross-validation. Psychological Reports, 34, 1184-1186.

Bijl, R. V., Ravelli, A., \& van Zessen, G. (1998). Prevalence of psychiatric disorder in the general population: Results of The Netherlands Mental Health Survey and Incidence Study (NEMESIS). Social Psychiatry and Psychiatric Epidemiology, 33, 587-595.

Boomsma, D. I., Beem, A. L., van den Berg, M., Dolan, C. V., Koopmans, J. R., Vink, J. M. de Geus, E. J., \& Slagboom, P. E. (2000). Netherlands twin family study of anxious depression (NETSAD). Twin Research, 3, 323-334.

Dolan, C. V., \& Boomsma, D. I. (1998). Optimal selection of sib pairs from random samples for linkage analysis of a QTL using the EDAC test. Behavior Genetics, 28, 197-206.

Eaves, L., \& Meyer, J. (1994). Locating human quantitative trait loci: Guidelines for the selection of sibling pairs for genotyping. Behavior Genetics, 24, 443-455.

Eysenck, H. J., \& Eysenck, S. B. G. (1964). Eysenck Personality Inventory. San Diego, CA: Educational Industrial Testing Service.

Eysenck, S. B. G., Eysenck, H. J., \& Barrett, P. (1985). A Revised Version of the Psychoticism Scale. Personality and Individual Differences, 6, 21-29.

Foley, D. L., Neale, M. C., \& Kendler, K. S. (1998). Reliability of a lifetime history of major depression: Implications for heritability and co-morbidity. Psychological Medicine, 28, 857-870.

Gillespie, N. A., Kirk, K. M., Evans, D. M., Heath, A. C., Hickie, I. B., \& Martin, N. G. (2004). Do the genetic or environmental determinants of anxiety and depression change with age? A longitudinal study of Australian twins. Twin Research, 7, 39-53.

Hettema, J. M., Neale, M. C., \& Kendler, K. S. (2001). A review and meta-analysis of the genetic epidemiology of anxiety disorders. American Journal of Psychiatry, 158, 1568-1578.

Hettema, J. M., Prescott, C. A., \& Kendler, K. S. (2001). A population-based twin study of generalized anxiety disorder in men and women. Journal of Nervous and Mental Diseases, 189, 413-420.

Hettema, J. M., Prescott, C. A., Myers, J. M., Neale, M. C., \& Kendler, K. S. (2005). The structure of genetic and environmental risk factors for anxiety disorders in men and women. Archives of General Psychiatry, 62, 182-189.

Hottenga, J. J., Boomsma, D. I., Kupper, N., Snieder, H., Posthuma, D., \& de Geus, E. J. (2005). Heritability and stability of resting blood pressure. Twin Research and Human Genetics, 499-508.

Jardine, R., Martin, N. G., \& Henderson, A. S. (1984). Genetic covariation between neuroticism and the symptoms of anxiety and depression. Genetic Epidemiology, 1, 89-107. 
Kendler, K. S., Gardner, C. O., Neale, M. C., \& Prescott, C. A. (2001). Genetic risk factors for major depression in men and women: Similar or different heritabilities and same or partly distinct genes? Psychological Medicine, 31, 605-616.

Kendler, K. S., Gardner, C. O., \& Prescott, C. A. (2001). Panic syndromes in a population-based sample of male and female twins. Psychological Medicine, 31, 989-1000.

Kendler, K. S., Jacobson, K. C., Myers, J., \& Prescott, C. A. (2002). Sex differences in genetic and environmental risk factors for irrational fears and phobias. Psychological Medicine, 32, 209-217.

Kendler, K. S., Karkowski, L. M., \& Prescott, C. A. (1999). Fears and phobias: Reliability and heritability. Psychological Medicine, 29, 539-553.

Kendler, K. S., Myers, J., Prescott, C. A., \& Neale, M. C. (2001). The genetic epidemiology of irrational fears and phobias in men. Archives of General Psychiatry, $58,257-265$.

Kendler, K. S., Neale, M. C., Kessler, R. C., Heath, A. C., \& Eaves, L. J. (1992). The genetic epidemiology of phobias in women: The interrelationship of agoraphobia, social phobia, situational phobia, and simple phobia. Archives of General Psychiatry, 49, 273-281.

Kendler, K. S., \& Prescott, C. A. (1999). A populationbased twin study of lifetime major depression in men and women. Archives of General Psychiatry, 56, 39-44.

Kendler, K. S., Prescott, C. A., Myers, J., \& Neale, M. C. (2003). The structure of genetic and environmental risk factors for common psychiatric and substance use disorders in men and women. Archives of General Psychiatry, 60, 929-937.

Kessler, R. C., McGonagle, K. A., Zhao, S., Nelson, C. B., Hughes, M., Eshleman, S., Wittchen, H. U., \& Kendler, K. S. (1994). Lifetime and 12-month prevalence of DSM-III-R psychiatric disorders in the United States. Results from the National Comorbidity Survey. Archives of General Psychiatry, 51, 8-19.

Kirk, K. M., Birley, A. J., Statham, D. J., Haddon, B., Lake, R. I., Andrews, J. G., \& Martin, N. G. (2000). Anxiety and depression in twin and sib pairs extremely discordant and concordant for neuroticism: Prodromus to a linkage study. Twin Research, 3, 299-309.

Kruijshaar, M. E., Barendregt, J., Vos, T., de Graaf, R., Spijker, J., \& Andrews, G. (2005). Lifetime prevalence estimates of major depression: An indirect estimation method and a quantification of recall bias. European Journal of Epidemiology, 20, 103-111.

Little, R. J. A., \& Rubin, D. B. (1987). Statistical analyses with missing data. New York: Wiley.

Martin, N. G., Jardine, R., Andrews, G., \& Heath, A. C. (1988). Anxiety disorders and neuroticism: Are there genetic factors specific to panic? Acta Psychiatrica Scandinavica, 77, 698-706.
Middeldorp, C. M., Cath, D. C., van den Berg, M., Beem, A. L., Van Dyck, R., \& Boomsma, D. I. (in press). The association of personality with anxious and depressive psychopathology. In T. Canli (Ed.), The biological basis of personality and individual differences. New York: Guilford Press.

Musselman, D. L., Evans, D. L., \& Nemeroff, C. B. (1998). The relationship of depression to cardiovascular disease: Epidemiology, biology, and treatment. Archives of General Psychiatry, 55, 580-592.

Neale, M. C., Boker, S. M., Xie, G., \& Maes, H. H. (1999). Mx: Statistical modeling (6th ed.). Richmond, VA: Department of Psychiatry, Medical College of Virginia.

Neale, M. C., \& Cardon, L. R. (1992). Methodology for genetic studies of twins and families. Boston, MA: Kluwer Academic.

Penninx, B. W., Beekman, A. T., Honig, A., Deeg, D. J., Schoevers, R. A., van Eijk, J. T., \& van Tilburg, W. (2001). Depression and cardiac mortality: Results from a community-based longitudinal study. Archives of General Psychiatry, 58, 221-227.

Risch, N., \& Zhang, H. (1995). Extreme discordant sib pairs for mapping quantitative trait loci in humans. Science, 268, 1584-1589.

Scherrer, J. F., True, W. R., Xian, H., Lyons, M. J., Eisen, S. A., Goldberg, J., Lin, N., \& Tsuang, M. T. (2000). Evidence for genetic influences common and specific to symptoms of generalized anxiety and panic. Journal of Affective Disorders, 57, 25-35.

Spielberger, C. D., Gorsuch, R. L., \& Lushene, R. E. (1970). STAI manual for the State-Trait Anxiety Inventory. Palo Alto, CA: Consulting Psychologists Press.

Sullivan, P. F., Neale, M. C., \& Kendler, K. S. (2000). Genetic epidemiology of major depression: Review and meta-analysis. American Journal of Psychiatry, 157, 1552-1562.

Van der Ploeg, H., Defares, P. B., \& Spielberger, C. D. (1979). Zelfbeoordelingsuragenslijst STAI, versie DY-1 en DY-2 [Self report questionnaire STAI, version DY-1 and DY-2]. Lisse, the Netherlands: Swets \& Zeitlinger.

Verhulst, F. C., van der Ende, J., \& Koot, H. M. (1997). Handleiding voor de Youth Self Report [Manual for the Youth Self-Report]. Rotterdam, the Netherlands: Afdeling Kinder- en Jeugdpsychiatrie, Sophia Kinderziekenhuis/Academisch Ziekenhuis Rotterdam/ Erasmus Universiteit Rotterdam.

Wilde, G. J. S. (1970). Neurotische labiliteit gemeten volgens de vragenlijstmethode [The questionnaire method as a means of measuring neurotic instability]. Amsterdam: Van Rossen.

World Health Organization (1992). Composite International Diagnostic Interview (Version 2.1). Geneva, Switzerland: Author. 